\section{Enhanced photooxidation sensitizers: the first examples of cyclometalated pyrene complexes of iridium(III) $\dagger$}

\author{
Andrew J. Hallett, ${ }^{a}$ Nathan White, ${ }^{a}$ Wanhua $W u,{ }^{b}$ Xiaoneng Cui, ${ }^{b}$ Peter N. Horton, ${ }^{c}$ \\ Simon J. Coles, ${ }^{c}$ Jianzhang Zhao ${ }^{b}$ and Simon J. A. Pope ${ }^{* a}$
}

Received 15th August 2012, Accepted 18th September 2012

DOI: $10.1039 / \mathrm{c} 2 \mathrm{cc} 35907 \mathrm{c}$

The iridium(III) cyclometalation of alkylated pyrene-benzimidazole ligands proceeds in an unprecedented manner. The resultant complexes display remarkably enhanced photooxidation capabilities using 1,5-dihydroxynaphthalene as a substrate.

The utility of organic singlet oxygen $\left({ }^{1} \mathrm{O}_{2}\right)$ photosensitizers such as porphyrins, phthalocyanines, fullerenes and biologically relevant molecules has been well established. ${ }^{1}$ Porphyrins, in particular, have attracted attention through their use in photodynamic therapy (PDT) and potential in cancer treatment, ${ }^{2}$ and efforts remain regarding targeting of agents to specific tissue locale. Beyond PDT, photosensitized oxidation can be applied to oxidative transformations in organic chemistry and catalysis, ${ }^{3}$ as well as applied avenues such as water disinfection ${ }^{4}$ and hydrogen production. ${ }^{5}$ General challenges remain regarding the optimum characteristics of ${ }^{1} \mathrm{O}_{2}$ photosensitizers, with the highly planarised organic systems suffering from aggregation in solution and compromised ${ }^{1} \mathrm{O}_{2}$ quantum yields; ${ }^{6}$ for alternative agents maximal exploitation of the visible wavelengths is also a key challenge.

Very recently cyclometalated iridium(III) complexes have emerged as an alternative class of ${ }^{1} \mathrm{O}_{2}$ photosensitizer. ${ }^{7}$ The heavy iridium atom facilitates efficient formation of triplet excited states localized on the complex, and it is these that transfer energy to the triplet ground state of oxygen $\left({ }^{3} \mathrm{O}_{2}\right)$ yielding ${ }^{1} \mathrm{O}_{2}$. The additional benefits of this class of photosensitizer are the synthetic variants that are achievable via stepwise addition of ligands to the iridium centre, potentially allowing control of key physical properties and functionality.

In this context, we describe a previously unreported class of iridium complex incorporating cyclometalated pyrene units,

${ }^{a}$ School of Chemistry, Cardiff University, Wales, UK.

E-mail: popesj@cardiff.ac.uk; Fax: +44(0)2920874030;

Tel: + 44 (0)2920879316

${ }^{b}$ State Key Laboratory of Fine Chemicals, School of Chemical Engineering, Dalian University of Technology, E208 West Campus,

2 Ling-Gong Road, Dalian 116012, P.R. China

${ }^{c} U K$ National Crystallographic Service, Chemistry, Faculty of Natural and Environmental Sciences, University of Southampton, Highfield, Southampton, SO17 1BJ, England, UK

$\dagger$ Electronic supplementary information (ESI) available: Experimental, characterisation, photooxidation data, DFT. CCDC 890951.

For ESI and crystallographic data in CIF or other electronic format see DOI: $10.1039 / \mathrm{c} 2 \mathrm{cc} 35907 \mathrm{c}$

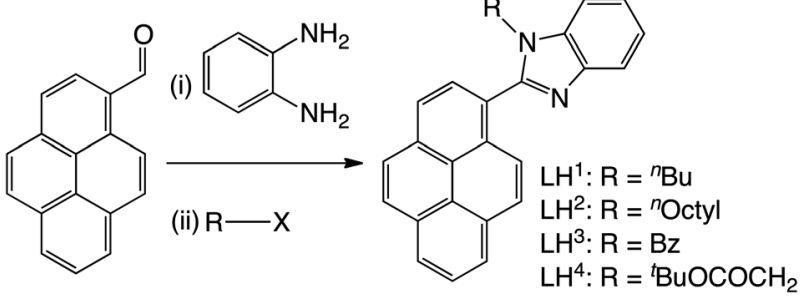

Scheme 1 Reaction conditions for the synthesis of the pyrenyl ligands. (i) heat, $\mathrm{PhNO}_{2}$; (ii) heat, 3-pentanone, $50 \% \mathrm{NaOH}, \mathrm{NPr}_{4} \mathrm{I}$.

additionally revealing the first structurally characterised cyclometalated chelate ring at iridium that is not an orthometalation. The incorporation of cyclometalated polyaromatic chromophores should improve the visible light absorption characteristics versus benchmark complexes such as $\left[\operatorname{Ir}(\mathrm{ppy})_{2}(\mathrm{bpy})\right]^{+}$ and $\left[\operatorname{Ir}(\mathrm{ppy})_{2}(\mathrm{acac})\right]$ and secondly, spin orbit coupling should facilitate the generation of triplet pyrene ( $\left.{ }^{3} \mathrm{pyr}^{*}\right)$ excited states, which in turn are very sensitive to dissolved oxygen. From the results reported herein, these new compounds appear to be extremely effective ${ }^{1} \mathrm{O}_{2}$ photosensitizers, as probed through a variety of studies utilising the ${ }^{1} \mathrm{O}_{2}$ scavenger 1,5-dihydroxynaphthalene (1,5-DHN).

The synthesis of the ligands (Scheme 1) was achieved in two steps: condensation of 1-pyrenecarboxaldehyde with 1,2-diaminobenzene gave the benzimidazole intermediate ${ }^{8}$ and subsequent $\mathrm{N}$-alkylation (using phase transfer conditions) gave a variety of species $\left(\mathbf{L} \mathbf{H}^{\mathbf{1 - 4}}\right)$ adorned with varying (R) side groups. The choice of alkylating group was determined to address issues of solubility and influences upon subsequent photooxidation performance. The iridium complexes were synthesised from $\mathrm{IrCl}_{3} \cdot x \mathrm{H}_{2} \mathrm{O}$ based on the Nonoyama method that we have used previously, ${ }^{9}$ wherein the chloro-bridged, cyclometalated dimer $\mathbf{I}(\mathbf{L})_{\mathbf{2}} \mathbf{I r}(\mu-\mathbf{C l})_{\mathbf{2}} \mathbf{I r}(\mathbf{L})_{\mathbf{2}} \mathbf{l}$ was firstly isolated; subsequent reaction with 2,2'-bipyridine yielded the mixed-ligand cationic species, $\left[\mathbf{I r}(\mathbf{L})_{\mathbf{2}} \mathbf{( b p y )}\right]\left(\mathbf{P F}_{\mathbf{6}}\right)$. However, in the reactions with ligands $N$-functionalised with $n$-octyl $\left(\mathbf{L}^{2}\right)$ and tert-butyl acetate $\left(\mathbf{L}^{\mathbf{4}}\right)$ groups, the predominant product from the reaction with $\mathrm{IrCl}_{3} \cdot x \mathrm{H}_{2} \mathrm{O}$ was the charge-neutral tris-cyclometalated complex $\left[\operatorname{Ir}(\mathbf{L})_{3}\right]$. This observation may be attributed to the relatively good solubility of the intermediate dimer species in these two cases. In contrast, the tris-cyclometalated complex of $\mathbf{L}^{\mathbf{3}}$ was best obtained in two steps; abstraction of the 
bridging chlorides of the dimer precursor with $\mathrm{AgNO}_{3}$ facilitated chelation of the third cyclometalating ligand, giving [Ir(L) $)_{3}$.

The ligands and complexes were characterised by the usual spectroscopic and analytical methods (see ESI $\dagger$ ) including ${ }^{1} \mathrm{H}$, ${ }^{13} \mathrm{C}\left\{{ }^{1} \mathrm{H}\right\}$ NMR spectroscopy and HR MS. An X-ray diffraction study was undertaken on $\left[\mathbf{I r}\left(\mathbf{L}^{\mathbf{3}}\right)_{\mathbf{2}}(\mathbf{b p y})\right]\left(\mathbf{P F}_{\mathbf{6}}\right)$ and revealed a highly unusual coordination mode for the pyrenyl ligands: rather than the available (and ubiquitous for $\mathrm{Ir}^{\mathrm{III}}$ ) orthometalation (i.e. at position $\mathrm{C} 2$ ), the preference here is for metalation at position $\mathrm{C} 10$ resulting in the formation of a six-membered ring. ${ }^{10}$ This is the first structurally characterised example of such a coordination mode at iridium (Fig. 1). The distorted octahedral coordination sphere also revealed close pyrene-pyrene contacts (3.155-3.606 ̊) apparently facilitated by a severe twist in the torsion angle between the imidazole and pyrene units (i.e. they are not co-planar). This very unusual binding mode allows accommodation of the highly bulky pyrene chromophores into the $\operatorname{Ir}($ III) coordination sphere whilst promoting favourable intramolecular $\pi-\pi$ interactions. Using this structural data, a single-point energy DFT calculation was obtained on $\left[\operatorname{Ir}\left(\mathbf{L}^{\mathbf{3}}\right)_{\mathbf{2}}(\mathbf{b p y})\right]^{+}$and revealed that the HOMO is localised on both pyrene units and $\operatorname{Ir}(5 \mathrm{~d})$ whilst the LUMO is on the ancillary bipyridine (Fig. S2, ESI $\dagger$ ).

Contrasting the optical properties with $\left[\operatorname{Ir}(\mathbf{p p y})_{\mathbf{2}}(\mathbf{b p y})\right]^{+}$, revealed increased molar absorptivities throughout the UV and visible regions for the complexes described here (Tables S3 and S4, Fig. S3, ESI $\dagger$ ). These enhanced absorption features

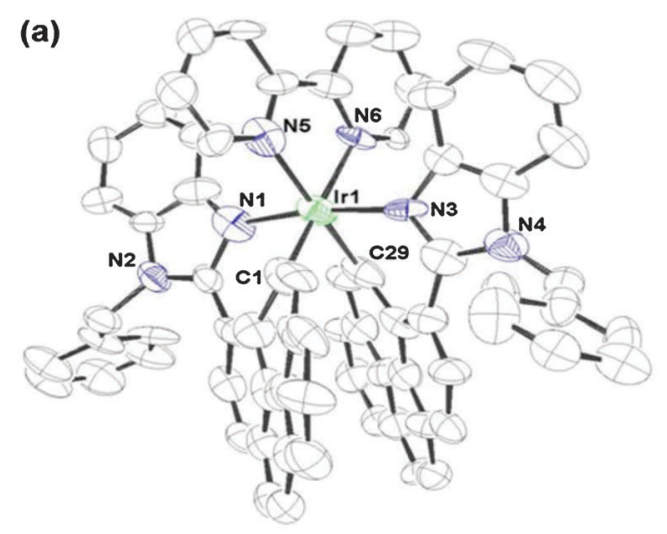

(b)

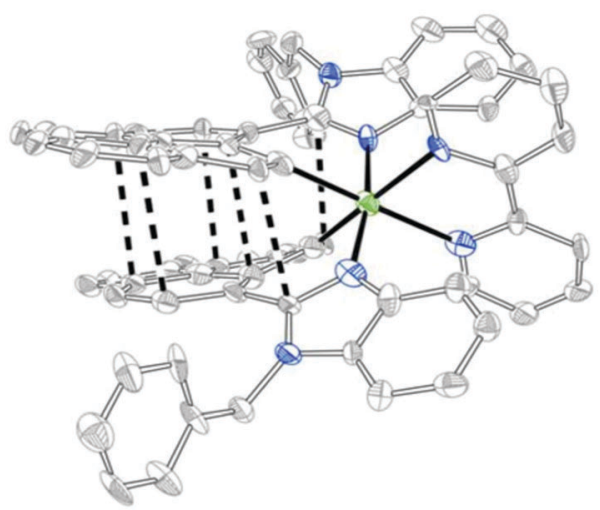

Fig. 1 Two views (a, b) of the X-ray crystal structure for $\left[\operatorname{Ir}\left(\mathbf{L}^{3}\right)_{2}-\right.$ (bpy) $\mathbf{(}\left(\mathbf{P F}_{\mathbf{6}}\right)$ revealing (b) the close intramolecular contacts of the cyclometalated pyrene units. can clearly be attributed to the presence of cyclometalated pyrenyl chromophores, with both ${ }^{1}$ IL (pyrene) and ${ }^{1}$ MLCT transitions contributing (spin orbit mediated ${ }^{3}$ MLCT transitions are also expected to contribute at longer wavelengths). ${ }^{11}$ The emission properties of the free ligands are also included for completion (Table S3, ESI $\dagger$ ) revealing structured, monomer-type fluorescence from the pyrene chromophores, which was insensitive to the nature of the substituent. ${ }^{12}$ In comparison irradiation of aerated solutions of the complexes revealed bathochromically shifted emission profiles between $407-446 \mathrm{~nm}$, with varying resolution of the vibronic definition (Fig. S4, ESI $\dagger$ ); similar emission wavelengths were observed for the complexes in the solid state. The associated lifetimes were all $<5 \mathrm{~ns}$, suggestive of a fluorescent emitting state, presumably localized on the pyrene-derived chromophore. The spectral appearance suggests a monomer-type emission although (intramolecular) excimer fluorescence cannot be ruled out ( $c f$. crystal structure). Somewhat unusually for Ir(III) complexes, the deoxygenated samples also showed identical emission profiles.

Analyses of the time-resolved transient difference absorption spectra (Table 1 and Fig. 2) for the four chosen complexes revealed the strong dependence of the triplet state lifetimes $\left(\tau_{\mathrm{T}}\right)$ on dissolved oxygen, with lifetimes dramatically extended in deoxygenated versus air-equilibrated solvent; the $\tau_{\mathrm{T}}$ values are significantly longer than that obtained for $\left[\operatorname{Ir}(\mathbf{p p y})_{\mathbf{2}}(\mathbf{b p y})\right]^{+}$ $(0.34 \mu \mathrm{s})$. The nature of the substituent also influences $\tau_{\mathrm{T}}$, although the effects for a given substituent are reversed for neutral versus cationic variants.

Importantly, the iridium complexes each demonstrated excellent photostability, which is a key prerequisite for the feasibility of future applications of such species. The benchmark assessment of the photooxidation capability of the complexes was performed using 1,5-dihydroxynaphthalene $(1,5-\mathrm{DHN}),{ }^{7}$ wherein the ${ }^{1} \mathrm{O}_{2}$ that is generated upon irradiation of the complex reacts with 1,5-DHN to give Juglone (Scheme S1, ESI $\dagger$ ), the formation of which is easily traced using UV-vis spectroscopy (see ESI $\dagger$ for details). Four complexes were selected for assessment in this manner, and the data associated with the ${ }^{1} \mathrm{O}_{2}$ generation, kinetics and yields of Juglone are presented in Table 1 together with $\left[\mathbf{I r}(\mathbf{p p y})_{\mathbf{2}}(\mathbf{b p y})\right]^{+}$ for contextual comparison.

The results show that the new complexes show up to tenfold larger rate constants compared to the model complex $\left[\operatorname{Ir}(\mathbf{p p y})_{\mathbf{2}}(\mathbf{b p y})\right]^{+}$(Table 1). The kinetics associated with the photooxidation studies showed that reactions proceed via a

Table 1 Pseudo-first-order kinetics parameters, ${ }^{1} \mathrm{O}_{2}$ generation quantum efficiencies triplet excited state lifetimes $\left(\tau_{\mathrm{T}}\right)$ and yields of Juglone for the photooxidations of 1,5-DHN using Ir complexes as sensitizers

\begin{tabular}{|c|c|c|c|c|c|}
\hline Compound & $\begin{array}{l}\tau_{\mathrm{T}}{ }^{a} / \\
\mu \mathrm{s}\end{array}$ & $\begin{array}{l}k_{\text {obs }} / \\
\text { min }^{-1}\end{array}$ & $\begin{array}{l}v_{\mathrm{i}}^{b} / \times 10^{-5} \\
\mathrm{M} \min ^{-1}\end{array}$ & $\Phi_{\Delta}^{c}$ & $\begin{array}{l}\text { Yield }^{d} \\
(\%)\end{array}$ \\
\hline$\left[\operatorname{Ir}(\mathbf{p p y})_{2}(\mathrm{bpy})\right]\left(\mathrm{PF}_{6}\right)$ & 0.34 & 0.0026 & 0.052 & 0.97 & 26.7 \\
\hline$\left[\operatorname{Ir}\left(\mathbf{L}^{1}\right)_{3}\right]$ & 8.0 & 0.021 & 0.42 & 0.52 & 79.0 \\
\hline$\left[\operatorname{Ir}\left(L^{4}\right)_{3}\right]$ & 15.0 & 0.015 & 0.30 & 0.43 & 75.5 \\
\hline$\left[\operatorname{Ir}\left(\mathbf{L}^{1}\right)_{2}(\mathbf{b p y})\right]\left(\mathbf{P F}_{6}\right)$ & 13.3 & 0.021 & 0.42 & 0.86 & 97.8 \\
\hline$\left[\operatorname{Ir}\left(\mathbf{L}^{3}\right)_{2}(\mathbf{b p y})\right]\left(\mathbf{P F}_{6}\right)$ & 3.9 & 0.035 & 0.70 & 0.80 & 99.2 \\
\hline
\end{tabular}

${ }^{a}$ Deoxygenated dichloromethane. ${ }^{b}$ Initial rate of DHN consumption. ${ }^{c}{ }^{1} \mathrm{O}_{2}$ generation quantum yield determined using the value of $\operatorname{TPP}\left(\Phi_{\Delta}=\right.$ 0.65 ) as a reference. ${ }^{d}$ Yield of Juglone after reaction for $60 \mathrm{~min}$. 

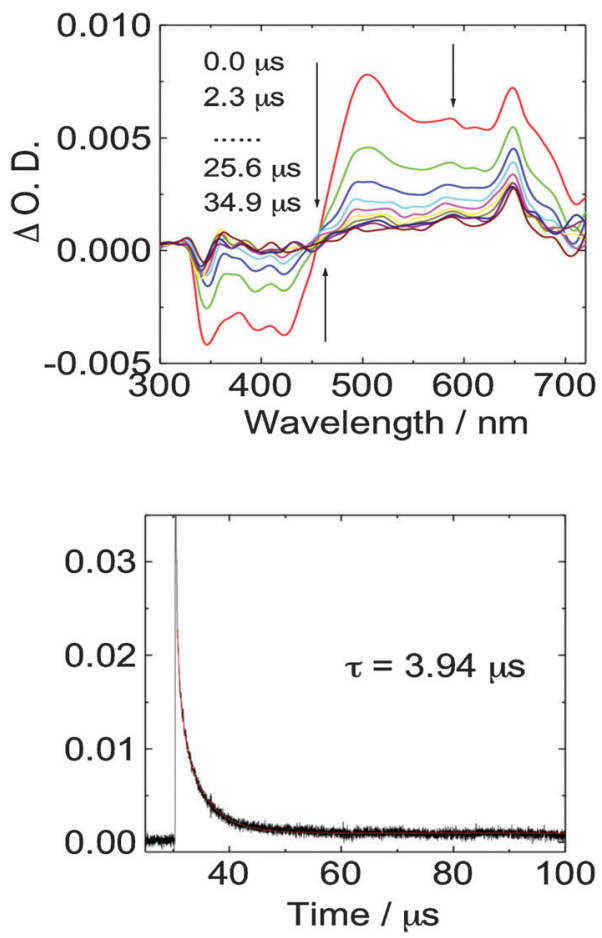

Fig. 2 Nanosecond time-resolved transient difference absorption spectra of (top) $\left[\mathbf{I r}\left(\mathbf{L}^{3}\right)_{\mathbf{2}}(\mathbf{b p y})\right]\left(\mathbf{P F}_{\mathbf{6}}\right)$ in de-aerated dichloromethane $\left(2.0 \times 10^{-5} \mathrm{M}, 25{ }^{\circ} \mathrm{C}\right)$. Arrows indicate the elapsed time after $355 \mathrm{~nm}$ laser flash. Bottom: fitted triplet state lifetime following the decay of the transients $(\lambda=510 \mathrm{~nm})$ in deoxygenated dichloromethane $\left(2.0 \times 10^{-5} \mathrm{M}\right.$, $\left.25^{\circ} \mathrm{C}\right)$.

pseudo first-order rate constant in each case (see Fig. S5, ESI $\dagger$ for plot of $\ln \left(C_{\mathrm{t}} / C_{0}\right)$ versus irradiation time). The ${ }^{1} \mathrm{O}_{2}$ quantum yields $\left(\Phi_{\Delta}\right)$ of the complexes were determined (Table 1); generally the new complexes show smaller $\Phi_{\Delta}$ values than the model complex $\left[\operatorname{Ir}(\mathbf{p p y})_{2}(\mathbf{b p y})\right]^{+}\left(\Phi_{\Delta}=0.98\right)$. To some extent the $\Phi_{\Delta}$ values can be regarded as an indication of the intersystem crossing (ISC) efficiency, and thus the observed $\Phi_{\Delta}$ values are in broad agreement with the photophysical studies on the new complexes. The observation of fluorescence, instead of phosphorescence, suggests that the ISC efficiency is not $100 \%$ for this class of complex. However, the smaller $\Phi_{\Delta}$ value is well compensated by the strong absorption of the complexes in the visible wavelength range. ${ }^{13}$ As a result, the DHN photooxidation efficiencies (Fig. S9, ESI $\dagger$ ) of the new complexes are much higher than that of the reference complex, $\left[\operatorname{Ir}(\mathbf{p p y})_{2}(\mathbf{b p y})\right]^{+}$.

Overall, the best performing complexes are the cationic variants, $\left[\operatorname{Ir}\left(\mathbf{L}^{3}\right)_{\mathbf{2}}(\mathbf{b p y})\right]\left(\mathbf{P F}_{\mathbf{6}}\right)$ and $\left[\operatorname{Ir}\left(\mathbf{L}^{\mathbf{1}}\right)_{\mathbf{2}}(\mathbf{b p y})\right]\left(\mathbf{P F}_{\mathbf{6}}\right)$, demonstrating comparable $\Phi_{\Delta}$ (despite the measured differences in $\tau_{\mathrm{T}}$ ), with remarkable, near-quantitative, yields of Juglone after $60 \mathrm{~min}$. As with the $\tau_{\mathrm{T}}$ values, the results also show that the nature of the substituent can influence the photooxidation behaviour, however, there is no apparent advantage to forming charge-neutral tris-cyclometalated species incorporating three pyrenyl ligands.
The development of functional sensitizers for photooxidation processes is a key scientific challenge and it is apparent that cyclometalated iridium complexes possess much promise in this regard. It is now clear that through the control of the ligand architecture such species can be advantageously tuned to this purpose. Cyclometalation of the pyrene-based ligands described has yielded unusually coordinated species, and provided a series of complexes that demonstrate remarkably enhanced photooxidation characteristics when compared to $\left[\operatorname{Ir}(\mathrm{ppy})_{2}(\mathrm{bpy})\right]^{+}$. The results show that the significantly tuned visible-light absorbing properties of the complexes are a key factor in their impressive photooxidation performance. Further work is currently underway to explore the broader utility and application of these highly performing ${ }^{1} \mathrm{O}_{2}$ generating complexes.

We thank the EPSRC for the use of the National Crystallographic Service at the University of Southampton ${ }^{14}$ and the MS National Service at the University of Swansea. J. Zhao thanks the support of NSFC (20972024 and 21073028).

\section{Notes and references}

1 (a) R. Bonnett, Chem. Soc. Rev., 1995, 24, 19; (b) E. L. Clennan and A. Pace, Tetrahedron, 2005, 61, 6665; (c) R. W. Redmond and J. N. Gamlin, Photochem. Photobiol., 1999, 70, 391; (d) A. W. Jensen, S. R. Wilson and D. I. Schuster, Bioorg. Med. Chem., 1996, 4, 767.

2 (a) R. R. Allison, Photodiagn. Photodyn. Ther., 2009, 6, 231; (b) S. Wang, R. Gao, F. Zhou and M. Selke, J. Mater. Chem., 2004, 14, 487; (c) P. Mroz, G. P. Tegos, H. Gali, T. Wharton, T. Sarna and M. R. Hamblin, Photochem. Photobiol. Sci., 2007, 6, 1139; (d) T. J. Dougherty, Photochem. Photobiol., 1987, 45, 879; J. D. Spikes, Photochem. Photobiol., 1986, 43, 691.

3 M. C. DeRosa and R. J. Crutchley, Coord. Chem. Rev., 2002, 233-234, 351.

4 O. Coppellotti, C. Fabris, M. Soncin, M. Magaraggia, M. Camerin, G. Jori and L. Guidolin, Curr. Med. Chem., 2012, 19, 808.

5 Y. J. Yuan, J. Y. Zhang, Z. T. Yu, J. Y. Feng, W. J. Luo, J. H. Ye and Z. G. Zou, Inorg. Chem., 2012, 51, 4123.

6 J. Moan, Photochem. Photobiol., 1984, 39, 445.

7 (a) R. Gao, D. G. Ho, B. Hernandez, M. Selke, D. Murphy, P. I. Djurovich and M. E. Thompson, J. Am. Chem. Soc., 2002, 124, 14828; (b) S. Takizawa, R. Aboshi and S. Murata, Photochem. Photobiol. Sci., 2011, 10, 895.

8 Y.-N. Yan, D.-Y. Lin, W.-L. Pan, X.-L. Li, Y.-Q. Wan, Y.-L. Mai and H.-C. Song, Spectrochim. Acta, Part A, 2008, 74, 233.

9 (a) M. Nonoyama, Bull. Chem. Soc. Jpn., 1974, 47, 767; (b) J. D. Routledge, A. J. Hallett, J. A. Platts, P. N. Horton, S. J. Coles and S. J. A. Pope, Eur. J. Inorg. Chem., 2012, 4065.

10 Note orthometalated systems that report six-membered rings: H. C. Li, P. T. Chou, Y. H. Hu, Y. M. Cheng and R. S. Liu, Organometallics, 2005, 24, 1329; Y. H. Song, Y. C. Chiu, Y. Chi, Y. M. Cheng, C. H. Lai, P. T. Chou, K. T. Wong, M. H. Tsai and C. C. Wu, Chem.-Eur. J., 2008, 14, 5423.

11 (a) S. Lamansky, P. Djurovich, D. Murphy, F. Abdel-Razzaq, R. Kwong, I. Tsyba, M. Bortz, B. Mui, R. Bau and M. E. Thompson, Inorg. Chem., 2001, 40, 1704; (b) A. J. Hallett, B. D. Ward, B. M. Kariuki and S. J. A. Pope, J. Organomet. Chem., 2010, 695, 2401; (c) D. L. Davies, M. P. Lowe, K. S. Ryder, K. Singh and S. Singh, Dalton Trans., 2011, 40, 1028.

12 J. B. Birks, in Photophysics of aromatic molecules, John Wiley and Sons, New York, 1970.

13 J. Sun, J. Zhao, H. Guo and W. Wu, Chem. Commun., 2012, 48, 4169-4171.

14 S. J. Coles and P. A. Gale, Chem. Sci., 2012, 3, 683. 